Aletria, Belo Horizonte, v. 29, n. 3, p. 21-38, 2019

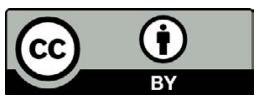

\title{
A teoria da literatura e as desumanidades
}

\section{Literature Theory and the Inhumanities}

\author{
Marcus Vinicius de Freitas \\ Universidade Federal de Minas Gerais (UFMG), Belo Horizonte, Minas Gerais / Brasil \\ marcus@letras.ufmg.br
}

Resumo: Este artigo busca analisar o desenvolvimento interno da Teoria da Literatura enquanto disciplina, e suas conexões com a perspectiva anti-humanista da Arte Moderna, tal como proposta por Ortega y Gasset. O anti-humanismo possui suas raízes na filosofia alemã do final do século XIX e na primeira metade do século XX, especialmente em autores tais como Nietzsche e Heidegger, e encontra seu desenvolvimento na filosofia francesa pós-moderna, tal como praticada por Michel Foucault e Jacques Derrida. O artigo reúne um conjunto de filósofos, sociólogos e críticos literários que se colocam como críticos da tendência anti-humanista nas ciências humanas, em especial autores tais como Luc Ferry e Alain Renaut, Roger Scruton, Eric Voegelin, Daniel Bell, José Guilherme Merquior, Raymond Tallis e Tzvetan Todorov, com vistas a discutir o papel histórico desempenhado pela Teoria da Literatura no conjunto das Humanidades, agora entendidas como Desumanidades.

Palavras-chave: teoria da literatura; anti-humanismo; pós-modernismo.

Abstract: This article aims at analyzing the internal development of Literary Theory as a discipline and its connection with the anti-human perspective of Modern Arts, concept once proposed by the Spanish philosopher Ortega Y Gasset. Such an anti-human perspective can be traced back in the German philosophy of the late 19th and early 20th centuries, especially among authors such as Nietzsche and Heidegger, as well as in its development towards a postmodern French philosophy, as practiced by Michel Foucault and Jacques Derrida. The article brings together a variety of philosophers, sociologists and literary critics who appraise the anti-human trend, notably Luc Ferry and Alain Renaut, Roger Scruton, Eric Voegelin, Daniel Bell, José Guilherme Merquior, Raymond Tallis and Tzvetan Todorov, among others, in order to discuss the role of Literary Theory as part of Humanities, now understood as Inhumanities.

Keywords: literary theory; anti-humanism; post-modernism.

eISSN: $2317-2096$

DOI: $10.17851 / 2317-2096.29 .3 .21-38$ 
Os estudos literários, que foram minha especialidade de origem, não me parecem muito prósperos em seu desenvolvimento atual. Escrevi um pequeno livro sobre o ensino de literatura na universidade e na escola secundária, traduzido também no Brasil, sobre a literatura em perigo, porque percebi que, tanto como historiador quanto como ensaísta, aproveitei mais da literatura em si mesma do que dos estudos sobre a literatura, e que lia com mais prazer romances, poemas e histórias diversas do que análises críticas literárias ou teses escritas sobre a literatura, as quais me parecem, hoje em dia, se dirigir quase exclusivamente aos outros especialistas da literatura, enquanto que o romance interessa a todo mundo. E me sinto mais próximo de todo mundo do que dos especialistas em tal ou tal assunto.

Tzvetan Todorov

A Teoria da Literatura constituiu-se como disciplina e saber especializado no começo do século XX, coetânea do momento heroico da chamada "Arte Moderna", e como tal, foi sempre marcada pelo caminho que aquela arte trilhou. Para sintetizar esse caminho da Arte Moderna, recorro à acertada expressão de Ortega y Gasset: trata-se de um processo de "desumanização da arte". Cabe aqui explicar mais detidamente o termo.

O filósofo espanhol escreveu o seu famoso ensaio, A desumanização da arte, em 1924, quando a arte modernista estava no auge da incompreensão popular. Segundo o filósofo, a nova arte dividia (e possivelmente ainda divide) o público em duas categorias: os que a entendem e os que não a entendem. Essa incompreensão deriva diretamente de sua desumanização, que seria a recusa do ponto de vista humano sobre o objeto artístico, substituindo-o por um ponto de vista propriamente artístico, ou seja, a desumanização constitui-se pelo ato de tomar o objeto artístico como linguagem, reconhecendo sua opacidade, e não como imagem do mundo ou das ações humanas. Nesse sentido, a Arte Moderna provocaria desentendimento por ser antirrealista, por fixar-se, antes, na linguagem que diz do que no que diz a linguagem. Vejamos a explicação dada por Ortega através do símile do jardim e do vidro da janela:

Trata-se de uma questão de óptica extremamente simples. Para ver um objeto, precisamos acomodar de certo modo o nosso aparelho ocular. Se a nossa acomodação visual é inadequada, não veremos o objeto ou o veremos mal. Imagine o leitor que estamos olhando um jardim através do vidro de uma janela. Nossos olhos se acomodarão de 
maneira que o raio da visão penetre o vidro, sem deter-se nele, e vá fixar-se nas flores e folhagens. Como a meta da visão é o jardim e até ele é lançado o raio visual, não veremos o vidro, nosso olhar passará através dele, sem percebê-lo. Quanto mais puro seja o vidro, menos o veremos. Porém logo, fazendo um esforço, podemos prescindir do jardim e, retraindo o raio ocular, detê-lo no vidro. Então o jardim desaparece aos nossos olhos e dele só vemos uma massa de cores confusas que parece grudada no vidro. Portanto, ver o jardim e ver o vidro da janela são duas operações incompatíveis: uma exclui a outra e requerem acomodações oculares diferentes. ${ }^{1}$

A obra de arte, no símile exposto, é o vidro, esse elemento que ao mesmo tempo deixa ver os fatos do mundo, mas os separa do sujeito que os contempla. Quem fixa o olhar no jardim não vê o vidro, pois quem contempla o fato não vê a linguagem que dá a ver o fato. Inversamente, quem detêm sua atenção sobre o vidro/linguagem, já não se interessa pelo jardim/mundo, mas apenas pelas puras virtualidades artísticas.

Cabe notar que, stricto sensu, ao nomear o procedimento da Arte Moderna como "desumanização", Ortega y Gasset não pretende levar o leitor a intuir e nem se reporta necessariamente a uma categoria antropológica negativa, mas a um conceito estético que se entende por "desrealização" ou "antirrealismo", o que seria uma forma de dizer que a nova arte não mais representa as coisas. Sob esse ponto de vista, a Arte Moderna, tal como compreendida por Ortega y Gasset, seria o lugar mesmo de demonstração do perspectivismo genealógico nietzscheano, que nega os fatos para enfatizar as interpretações. Diz Nietzsche:

Contra o positivismo, que permanece junto ao fenômeno afirmando "só há fatos", eu diria: não, precisamente não há fatos, apenas interpretações. Nós não podemos constatar nenhum fato "em si": talvez seja um disparate, então, querer algo assim. "Tudo é subjetivo", vocês dizem: mas isto já é interpretação. O sujeito não é nada dado, mas algo anexado, colocado por trás. - É por fim necessário colocar ainda o intérprete por trás da interpretação? Já isto é poesia, hipótese. Na medida em que a palavra

${ }^{1}$ ORTEGA Y GASSET. A desumanização da arte, p. 27. 
"conhecimento" faz sentido, o mundo é cognoscível: mas ele é passível de receber outras explicitações, ele não possui nenhum sentido por trás de si, mas inúmeros sentidos, "Perspectivismo". ${ }^{2}$

Entretanto, apesar da posição aparentemente neutra da explicação dada por Ortega y Gasset, não há como não ver, nos dois casos - tanto no estetismo da Arte Moderna, quanto na crítica genealógica de Nietzsche -, a umbilical ligação entre a desumanização, enquanto procedimento estético ou cognitivo, e o anti-humanismo, enquanto crítica da filosofia humanista que caracterizou a Modernidade. Nesse sentido, a arte modernista é o lugar por excelência da crítica à Modernidade e a seu humanismo. De fato, a "poética da negatividade", que caracteriza a Arte Moderna, é negativa propriamente em relação às figuras do homem, o que transparece na sua busca intencional do estranhamento, da despersonalização, da dissonância, e de todo um léxico de "categorias negativas", como aponta Hugo Friedrich, em seu estudo da lírica moderna. ${ }^{3}$ A Teoria da Literatura, nascida como derivado e suporte da literatura moderna, e ao mesmo tempo, nascida sobre o solo da crítica ao humanismo moderno, encetada por pensadores como Nietzsche, Marx e Freud, não poderia senão trazer essas marcas ao longo de seu desenvolvimento no século XX.

A crítica ao humanismo moderno se configura naquilo que correntemente chamamos de Modernismo, ou seja, o Modernismo é contrário à cultura moderna. A frase aparenta uma contradição, e para dirimi-la necessitamos distinguir os termos. A cultura moderna, na definição de Daniel Bell, é aquela que se sustenta na tríade capitalismo, democracia liberal e autorrealização do indivíduo. Nesse quadro, a razão e a ciência aparecem como estratégias de unificação da compreensão humana da natureza e do sentido do mundo, sobretudo em substituição à religião. ${ }^{4}$ No entanto, aponta Bell, a extraordinária liberdade da cultura moderna não a isenta de contradições, em especial aquelas que ocorrem entre as estruturas sociais tecno-econômicas, que são burocráticas e hierárquicas, e as estruturas políticas, que acreditam, formalmente, em igualdade e participação; entre as estruturas sociais, que são basicamente organizadas em termos de papéis e especialização, e a cultura, que se

\footnotetext{
${ }^{2}$ NIETZSCHE. Assim falou Zaratustra, p. 34-35.

${ }^{3}$ FRIEDRICH. Estrutura da lírica moderna, 19 et seq.

${ }^{4}$ BELL. The Cultural Contradictions of Capitalism, p. 13-14, tradução minha.
} 
volta para a autorrealização do eu. ${ }^{5}$ Bell nos lembra que a filosofia de Nietzsche se assenta numa denúncia dessas contradições, porque, para o filósofo, elas levariam ao niilismo moderno, negação de toda expressão espontânea. Para Nietzsche, diz Bell, a fonte de todo o niilismo seriam o racionalismo e o cálculo, em última instância, a ciência moderna. Nesse sentido, o filósofo estaria além da filosofia moderna, e mais propriamente deveria ser visto como um filósofo modernista. Ou seja, Daniel Bell está nos dizendo que o Modernismo e os modernistas são a face crítica e avant garde da cultura moderna, que se volta contra a própria Modernidade no que ela possui de hierárquico e racional. $\mathrm{O}$ capitalismo, o liberalismo, a razão científica e a democracia constituem assim os alvos do Modernismo, que preza, sobretudo, a substituição da moral por uma justificativa estética da vida. Mais do que criar uma obra de arte, o modernista busca viver a vida como uma obra de arte, busca ser uma obra de arte. Diz Bell: "eu vejo o Modernismo como a instância de agenciamento da dissolução da mundividência burguesa". E continua o autor:

Tematicamente, o Modernismo se assenta na revolta contra a ordem, em particular a ordem burguesa; sua ênfase recai no "eu", e na busca incessante de novas experiências. Se Terêncio costumava dizer 'nada humano me é estranho', o modernista poderia dizer com igual fervor, 'nada inumano me é estranho'. O racionalismo é visto como desvitalizante; a criatividade tem seu combustível em uma exploração do demoníaco. Nessa exploração, não há limites estéticos (ou normas morais) para o alcance proteano da imaginação. ${ }^{6}$

Daniel Bell sustenta sua análise das contradições do capitalismo, sobretudo na emergência estética do Modernismo. E lembro que os termos do autor ao parodiar o dito do poeta latino Terêncio, nos remetem novamente ao tema do "inumano", anteriormente visto com Ortega y Gasset. Há que se destacar ainda, no raciocínio de Daniel Bell, que ele engloba na revolta modernista a sua vertente ainda mais radical - o avant garde do avant garde -, qual seja, o Pós-Modernismo, que não seria mais do que o ato de levar a lógica do Modernismo aos últimos limites.

\footnotetext{
${ }^{5}$ BELL. The Cultural Contradictions of Capitalism, 14, tradução minha.

${ }^{6}$ BELL. The Cultural Contradictions of Capitalism, p. xxi, tradução minha.
} 
Entre esses limites, como veremos mais à frente, está o de estetizar o pensamento, o de tornar toda reflexão teórica uma espécie de arte moderna do pensamento, ou seja, de transformá-la em um pensamento que não representa nada a não ser a si mesmo, um pensamento performático, da mesma forma em que a Arte Moderna caminhou pela não-figuratividade para alcançar a pura performance.

Antes de voltar-me especificamente para a história da Teoria da Literatura em sua relação com as ciências humanas, pensada essa Teoria contra o pano de fundo do Modernismo anti-moderno, quero apenas mencionar três filósofos que fazem coro com o sociólogo Daniel Bell em sua análise da distinção entre moderno e modernista, seja no campo da filosofia, seja no campo da arte ou da cultura. São eles Roger Scruton, Luc Ferry e Alain Renaut.

Roger Scruton, um filósofo de formação analítica, claramente distingue a filosofia moderna de seu ramo modernista e pós-modernista. São muitos os locais onde essa distinção se faz na obra do filósofo inglês. Lembro, entre outros, o livro Modern Philosophy: an introduction and survey. ${ }^{7}$ Uma boa introdução ao pensamento do autor, no que concerne a uma crítica do Modernismo e do Pós-Modernismo em filosofia, pode ser encontrada no artigo "Confessions of a Sceptical Francophile" ou ainda nas suas memórias, intituladas Gentle Regrets, em especial o capítulo em que narra sua experiência como jovem estudante na Paris de $1968 .{ }^{9}$

Luc Ferry e Alain Renaut dedicaram todo um livro à crítica da filosofia pós-moderna francesa, intitulado Pensamento 68: ensaio sobre o anti-humanismo contemporâneo (1988), no qual as relações entre essa vertente filosófica e o horizonte do Modernismo são devidamente enfocadas. Livro esse, infelizmente, com pouca recepção entre nós brasileiros, apesar de já ter sido publicado há trinta anos. Cabe lembrar que o livro antes citado de Daniel Bell traz um capítulo intitulado "The Sensibility of the Sixties", que vai na mesma direção, mostrando a convergência desses autores. As análises de Ferry e Renaut são muito preciosas quando procuramos entender o lugar hodierno da Teoria da Literatura como derivada direta do pensamento dos chamados soixante-huitards.

\footnotetext{
${ }^{7}$ SCRUTON. Modern Philosophy: An Introduction and Survey, cap. 1, p. 1-15; SCRUTON. Modern Philosophy: An Introduction and Survey, cap 30, p. 458-480.

${ }^{8}$ SCRUTON. Confessions of a Sceptical Francophile.

${ }^{9}$ SCRUTON. Gentle Regrets, p. 33-56.
} 
No caso da compreensão da postura modernista e pós-modernista como crítica à Modernidade, mais importante ainda é o livro de Luc Ferry intitulado $A$ nova ordem ecológica: a árvore, o animal e o homem. Nesse texto, o autor propõe que o humanismo pode ser visto como um hiato moderno entre um tempo pré-moderno e um tempo pós-moderno, que se irmanam em oposição ao tempo moderno através de sua colocação da natureza como sujeito de direito, ou seja, prémodernos e pós-modernos veem a natureza como sujeito moral, fato patente nos debates contemporâneos sobre a animalidade, colocada no coração mesmo da discussão das relações do homem com a natureza, debate que ecoa antigas discussões semelhantes, ocorridas na França em momento anterior ao Iluminismo. Ao analisar a vertente ecológica que se autonomeia "ecologia profunda", Ferry mostra como ela é capaz de aliar em um mesmo movimento "[...] teses tradicionais da extrema direita com motivos futuristas da extrema esquerda. O essencial, o que dá coerência ao conjunto", diz Ferry, "[...] é o cerne do diagnóstico: a modernidade antropocentrista é um total desastre". Porque a modernidade antropocêntrica buscaria a uniformidade, o consenso e a universalidade, seus críticos têm como estratégia, segundo o autor, "[...] o elogio da diversidade, da singularidade, da particularidade, por conseguinte tanto do 'local' (versão esquerda da ecologia profunda) quanto do 'nacional' (versão direita)". ${ }^{10}$

Uma vez colocado esse quadro, podemos voltar à afirmação antes feita de que a Teoria da Literatura nasce de e para o Modernismo, e assim se constitui indelevelmente com aquelas marcas da crítica ao humanismo.

Não é necessário repetir aqui o percurso histórico da disciplina, basta lembrar que, do Formalismo ao Estruturalismo, a Teoria caminhou a passos largos para o reconhecimento do lugar central da linguagem na obra de arte. ${ }^{11}$ O Formalismo Russo trouxe enorme contribuição para os estudos de literatura ao recusar a ênfase crítica do Romantismo na figura do autor e na expressão de seu gênio. Ao assim fazer, os formalistas chamaram a atenção para os processos construtivos da obra literária na sua dimensão linguística, o que fez a obra passar a ser compreendida como um sistema, um conjunto de funções. Daqui ao Estruturalismo, o passo foi dado por Lévi-Strauss, ao reconhecer na fonologia estrutural de

\footnotetext{
${ }^{10}$ FERRY. A nova ordem ecológica: a árvore, o animal e o homem, p. 35-36.

${ }^{11}$ Para uma visão detalhada, ver MERQUIOR. De Praga a Paris, 1991.
} 
Troubetzkoy o modelo científico que deveria ser seguido pelas ciências humanas. Para que as ciências humanas atingissem maturidade científica, três condições deveriam ser satisfeitas, segundo o antropólogo: a) ter um objetivo universal vigente em todas as sociedades; $b$ ) ter um método homogêneo, independente da área de aplicação; e c) possuir pressupostos e métodos que fossem consensuais entre os praticantes da disciplina. Como corolário dessa ênfase na análise do processo construtivo e das estruturas de linguagem da obra, e não na figura do construtor, a Teoria, seguindo os pressupostos da antropologia de Lévi-Strauss, e calcada na linguística, trouxe grandes contribuições para os estudos da arte literária. Mas essa mesma ênfase na análise linguística trouxe como consequência uma espécie de esquecimento de que a literatura é, antes de tudo, uma crítica da vida, e não um construtor de linguagem que se basta.

Ao mesmo tempo, essa mesma perspectiva linguística da teoria da literatura deixou aberta a porta para uma crítica generalizada do papel do indivíduo criador. O horizonte final desse sequestro é a chamada "morte do autor", proclamada pelo crítico Roland Barthes no começo dos anos 1970, como versão metonímica da proclamada "morte do homem", ditada por Michel Foucault nas páginas finais de As palavras $e$ as coisas. ${ }^{12} \mathrm{O}$ advento das estruturas decretou a morte do sujeito. Essa morte (ou esse assassinato) se assenta em dois pilares da filosofia e das ciências humanas a partir dos anos 1960: a) a ênfase na estrutura e na linguagem, impulso que se degrada em uma visão de que todo conhecimento e a própria realidade constituem apenas discurso, ou texto, o que levou à prática propriamente pós-estruturalista e desconstrucionista do pensamento estetizado, e ainda ao corolário de que, se não há fatos, apenas interpretações, não há limites para o desejo, essa pedra de toque dos acontecimentos e da ideologia anti-normativa de maio de 68 ; b) um radical anti-humanismo, que tinha suas raízes nas genealogias interpretativas de Nietzsche, mas que, passando por Heidegger, encontrou solo fértil naquela concepção do conhecimento como pura linguagem e da realidade como texto, anti-humanismo alimentado paralelamente pela herança cultural do Modernismo, não apenas em função de sua arte desumanizada, que estanca a representação no limite da própria linguagem artística, mas igualmente por seu viés contracultural. Esses dois pilares - por um

${ }^{12}$ FOUCAULT. As palavras e as coisas, p. 403-404 
lado o descolamento entre a linguagem e o mundo, e por outro o antihumanismo - se completam no amálgama de uma única fundação.

Luc Ferry e Alain Renaut demostram com rigor a presença do anti-humanismo na filosofia francesa dos anos 1960, através de uma tipificação do que chamam de "pensamento 68", cuja estrutura intelectual é encarnada por um tipo ideal que possui quatro características, a saber: 1) a recorrência ao tema do "fim da filosofia", tentativa de romper com toda a corrente filosófica que vem de Platão até hoje; 2) a tomada da genealogia interpretativa como paradigma da atividade filosófica, genealogia que trata todo discurso consciente como sintoma, e portanto não busca apreender o seu conteúdo, mas antes interrogar as suas condições exteriores de produção, quer seja essa interrogação formulada como crítica do Ser, na tradição nietzscheana-heideggeriana (crítica da metafísica da presença); quer como elogio da libido, na tradição freudiana; ou ainda como desvalorização das chamadas superestruturas ideológicas, em favor da infraestrutura econômica, na tradição marxista; 3) a dissolução da ideia de verdade, pois, se a verdade é pensada tradicionalmente como adequação entre sujeito e coisa, ela já não faz sentido quando se postula que não há mais referente, uma vez que a linguagem basta a si mesma (o que, aliás, já vimos em relação à Arte Moderna); 4) a completa historicização das categorias e o fim de qualquer referência ao universal, ao mesmo tempo em que a essa historicidade se recusa qualquer encadeamento causal, substituído por uma história descontínua. ${ }^{13}$

Essas quatro características, segundo Ferry e Renaut, permeiam a filosofia ligada ao Maio de 68, em especial à de seus quatro maiores anti-humanistas (Foucault, Derrida, Bourdieu e Lacan), que repetem e aprofundam, na terra de Descartes, os temas do anti-humanismo alemão do final do século XIX e da primeira metade do século XX, não por acaso a mesma época heroica da Arte Moderna e de sua crítica à Modernidade.

Nessa relação entre os pensadores de maio de 68 e os pensadores anti-humanistas que os precederam, Ferry e Renaut seguem de perto o raciocínio de Daniel Bell, para quem a contracultura (ou seja, a crítica da cultura moderna, praticada em larga escala a partir de Maio de 68) deriva diretamente do Alto Modernismo, com uma diferença: o que agora ocupa o largo espaço da cultura massificada era antes restrito

${ }^{13}$ FERRY; RENAUT. Pensamento 68: ensaio sobre o anti-humanismo contemporâneo, p. 26-34. 
ao ambiente da arte e do pensamento de vanguarda. ${ }^{14}$ Por isso, José Guilherme Merquior, seguindo o mesmo Daniel Bell, afirma que o "o estruturalismo e sua sucessão devem ser vistos como as forças principais de uma colonização do pensamento pela ideia modernista na literatura e na arte". ${ }^{15}$ E continua o crítico:

O que certa vez foi pensado e simbolizado pelo artista de vanguarda é agora o que crê e pratica (pelo menos em princípio) o estudante rebelde, o acadêmico radical, em acontecimentos públicos e na subcultura punk. Para ser exato, todos esses grupos ainda são, em termos numéricos, uma minoria dentro da sociedade maior, burguesa e aburguesada. Mas, ao contrário das vanguardas realistas, eles estão se tornando o público principal da alta cultura, consequentemente fortalecendo de forma considerável o ataque modernista contra a modernidade. ${ }^{16}$

Como se dá essa colonização, em termos da teoria e da reflexão, e não apenas em termos de práticas e acontecimentos? Dá-se através da assimilação, pela Teoria, da antifiguratividade da Arte Moderna, que antes vimos no símile da janela e do jardim, exposto por Ortega y Gasset. De fato, conclui Merquior:

A teoria pós-estruturalista é a arte moderna do pensamento: deleita-se na sua própria antifiguratividade obstinada. Equivale a um Alto Modernismo intelectual (oposto ao literário e artístico), mantendo o mesmo ódio contra a modernidade no seu sentido histórico-social. [...] Karl Kraus chamou sarcasticamente a psicanálise a doença da qual ela alega ser a cura. Da mesma forma, a teoria niilista pode ser descrita como a crise cultural da qual ela pretende ser um diagnóstico. ${ }^{17}$

Ferry e Renaut voltam a esse mesmo tema do pensamento estetizado quando mostram que o fim da filosofia, tal como preconizado

\footnotetext{
${ }^{14}$ BELL. The Cultural Contradictions of Capitalism, p. 53-54, tradução minha.

${ }^{15}$ MERQUIOR. De Praga a Paris, p. 246.

${ }^{16}$ MERQUIOR. De Praga a Paris, p. 276.

${ }^{17}$ MERQUIOR. De Praga a Paris, p. 276.
} 
por Derrida na Gramatologia, encontra a mesma atitude de pensamento performático:

Ao mesmo tempo apoiada numa representação heideggeriana do fim da filosofia como metafísica, a Grammatologie explicava, com efeito, que a desconstrução da metafísica deveria permitir ao pensamento se libertar finalmente de seu aprisionamento "dentro desta época de onto-teologia, dentro desta filosofia da presença, isto é, dentro da filosofia". Contra a filosofia que "no passado" tinha sido invariavelmente uma filosofia "da presença", marcada pela obsessão de um significado presente por trás das palavras e por trás das aparências, Derrida se dirigia à prática de um pensamento que "não quer dizer nada" e que pretende ser um puro indício, uma pura significação, sem significado originário. ${ }^{18}$

Eric Voegelin - filósofo cuja preocupação incessante ao longo de toda a sua imensa obra pode ser resumida como a análise e o desmascaramento do papel das ideologias no século XX - afirma que, a partir do final do século XIX, entramos numa era de "perda da realidade", e essa perda é o que gera o papel preponderante das ideologias políticas ao longo do século XX. Para Voegelin, a perda da realidade, e a entrada no que o filósofo, na senda de Robert Musil e Karl Kraus, chama de "segunda realidade", se expressa em primeiro lugar, e de maneira patente, em situações políticas nas quais

[...] a língua em sua função real como mediadora entre o homem pensante e a realidade torna-se oca dentro de um molde que tem sua própria estrutura particular e, portanto, já não se relaciona com a realidade - ou seja, quando a língua mesma se torna uma segunda realidade dentro da qual se trabalha. É por isso que essas coisas aparecem. [...] Se alguém se diverte com a segunda realidade, a língua também se torna parte dela e surgem esses problemas que, na verdade, são apenas semânticos e resolvem-se tão logo se começa a pensar. Eles surgem apenas se não se pensa em relação à realidade, mas dentro da própria linguagem

${ }^{18}$ FERRY; RENAUT. Pensamento 68: ensaio sobre o anti-humanismo contemporâneo, p. 27-28. 
- resumidamente, se surge a situação que Heidegger formula, ou seja, a situação em que a "linguagem fala". Não é certamente a intenção de Heidegger caracterizar a linguagem como segunda realidade, mas ele de fato o fez. Ou seja, se a linguagem fala, então o contato entre o pensamento e a linguagem e entre o objeto e a realidade é interrompido, e esses problemas surgem porque já não se pensa em relação à realidade. ${ }^{19}$

Voegelin está descrevendo a crise de representação da linguagem captada em Heidegger, mas igualmente em Nietzsche, Freud e Marx (não por acaso, diríamos nós), pensadores que, segundo ele, possuiriam, a despeito das diferenças de suas disciplinas, três traços comuns reconhecíveis: a) todos eles concordam que o homem deve ser entendido da perspectiva do poder, do conflito e do instinto. São portanto, todos eles filósofos da libido; b) todos eles se preocupam em denunciar os valores como máscaras de interesses, conflito e instinto; c) em terceiro lugar, todos eles se caracterizam pelo ódio ao cidadão - do financista e industrial até o pequeno burguês -, ódio esse que corresponde à sua aristocracia intelectual (lembremos aqui do espírito aristocrático do Alto Modernismo). ${ }^{20}$ Como se pode ver, Voegelin, por outros caminhos, chega ao mesmo diagnóstico de Ferry \& Renaut, de Daniel Bell ou de Merquior. Em todos eles, o sintoma principal das ciências humanas ao longo do século XX é o da colocação da linguagem no lugar da própria realidade, prática que foi anunciada pela Arte Moderna, mas que invadiu as ciências do homem.

Aqui estamos no centro dos fatos que colocam a Teoria da Literatura como exemplo acabado desse processo niilista que soma antihumanismo, elogio da pura linguagem em detrimento do conhecimento, negação dos fatos do mundo em favor do jogo de interpretações, destruição da subjetividade pela atitude genealógica, e, não menos importante, soma ainda a prática de um pensamento vazio. De fato, dizem Luc Ferry e Alain Renaut:

Se, de um ponto de vista teórico, a genealogia, retirando $a$ priori do sujeito o controle de seus enunciados, participa claramente desta destruição da subjetividade em torno da qual se unem os componentes do pensamento 68, ela

${ }^{19}$ VOEGELIN. Hitler e os alemães, p. 324-325.

${ }^{20}$ VOEGELIN. Hitler e os alemães, p. 335-336. 
apresenta, além disso, praticamente efeitos perversos, onde o menor não é o delírio interpretativo. A crítica literária dos sixties também pagou seu tributo à adoção sistemática dessa démarche. ${ }^{21}$

Ao final dos anos 1960, os teóricos da literatura se viram no epicentro de um ambiente cultural que parecia reduzir os discursos da verdade (seja a filosofia ou a ciência) a puro jogo de linguagem, contexto em que, de maneira não menos importante, tomava-se como modelo intelectual a postura contracultural da Arte Moderna. Essa postura contracultural levou à politização da teoria, com a emergência do Estudos Culturais, que focam nos sujeitos da cultura, o que poderia aparentar um retorno a uma perspectiva humanista universalizante, o que, no entanto, se frustra pela permanência em seu interior da recusa antihumanista de encontrar quaisquer universais, e condena a multiplicidade de sujeitos da cena contemporânea a uma regressão localista, pré-moderna. Paralelamente ao evento dos Estudos Culturais, o sujeito voltou à cena através de uma parcial recuperação da figura do autor pelos novos estudos dos arquivos pessoais de escritores, uma forte corrente analítica que se foca nos documentos autorais como maneira de investigar o processo de criação literária. Mas, mesmo aqui, o anti-humanismo se faz presente, uma vez que o arquivo literário é enfocado, sobretudo, como arranjo autônomo produzido por um autor vazio, que se encena todo o tempo, reiterando uma vez mais o descolamento entre mundo e linguagem. Com certeza, não se trata de defender uma posição ingênua que igualasse arquivo, documento e verdade, posição simplista que aceitaria como transparente o papel da linguagem, mas apenas de apontar a desfuncionalidade de, a partir da autonomia do campo da literatura, deduzir-se um tanto abusivamente a invasão da realidade pela textualidade, transformando os arquivos e os documentos em puros jogos de linguagem, como se os escritores escrevessem para dentro de seus arquivos, e não em direção ao leitor e ao mundo. Dizendo de outra forma, a opacidade do meio não deveria ser justificativa para o abandono de um horizonte de representação da realidade no trato com os objetos autônomos de linguagem.

Esse equilíbrio precário entre autonomia e representação seria fator positivo para uma reavaliação da disciplina "teoria da literatura",

${ }^{21}$ FERRY; RENAUT. Pensamento 68: ensaio sobre o anti-humanismo contemporâneo, p. 117. 
pois, uma vez rompido definitivamente o equilíbrio, ao final dos anos 1960, a teoria passou a ser uma espécie de modelo em miniatura de uma tendência generalizada no campo das ciências humanas e sociais: a redução do mundo à linguagem.

Cabe aqui uma menção às pioneiras e metódicas críticas ao pósmodernismo e ao desconstrucionismo, empreendida por dois autores ingleses anteriores ao citado Roger Scruton, que permanecem pouco divulgados entre nós, apesar da completa e hodierna validade de seus argumentos. O primeiro é Raymond Tallis. Em Not Saussure-A Critique of Post-Saussurean Literary Theory e em In Defense of Realism, ambos de 1988, com edições posteriores, Tallis debate uma a uma as premissas da crítica pós-moderna, mostrando as suas falhas. No prefácio à segunda edição de In Defense of Realism, de 1998, o autor faz uma afirmação que parece bastante adequada a uma discussão sobre o lugar da teoria da literatura hoje:

Há luz no fim do túnel, e está perto o tempo em que historiadores estarão perscrutando as ruinas da Teoria e se perguntando como a praga do nonsense que desceu sobre as humanidades na década de 1960 durou tanto. ${ }^{22}$

O segundo autor de grande importância nesse contexto é Ernest Gellner, inglês por adoção, cujo livro Razão, religião e pós-modernismo constitui um marco da crítica ao pós-modernismo, sobretudo ao demonstrar o modo como as suas marcas se expandiram da crítica literária para outras ciências humanas e sociais.

Eric Voegelin, como já mencionamos, observa que o mergulho na "linguagem que fala", ou seja, a assunção da linguagem como segunda realidade e substituta do mundo, abre caminho para uma visão ideológica desse mesmo mundo. Sim, porque se a linguagem se apresenta como sistema autotélico e vazio, sem relação com o mundo concreto e real, ela pode facilmente ser preenchida pela vontade de poder e pela imaginação utópica de quem a controla, com o intuito de assim colocar seu projeto de mundo no lugar mesmo da realidade. Os projetos utópicos se fazem com poética e retórica, tomadas como substitutos da realidade. Por isso, o trabalho dos pensadores pós-modernos pode ser sumarizado como um esforço de redução da realidade e da verdade a uma construção retórica

${ }^{22}$ TALLIS. In Defense of Realism, p. ix, tradução minha. 
e poética. Não é outra a afirmação de Gianni Vattimo: "a experiência pós-moderna (isto é, heideggerianamente, pós-metafísica) da verdade é uma experiência estética e retórica". ${ }^{23}$ Esvaziando o horizonte de realidade necessário a toda busca de conhecimento, passa-se a viver no mundo virtual da própria linguagem, no qual o conhecimento é função da sedução, e logo de propaganda, não de convencimento.

No plano da universidade, esse estado de coisas possui duas outras consequências importantes, além daquelas já apontadas. A primeira consequência tem caráter interno à instituição, e se caracteriza pelo fato de que se criou, em seu interior, uma espécie de incompreensão entre as áreas que se pautam pela racionalidade da investigação e aquelas outras, nas quais a linguagem autotélica, o pensamento estetizado e o antihumanismo constituem largamente os protocolos de ação. Curiosamente, as instâncias de fomento e os fóruns inter e intrainstitucionais ainda nos denominam "humanidades", quando não temos mais praticado ciências humanas, e sim ciências inumanas, ou Desumanidades. Um bom exemplo está no documento da Academia Brasileira de Ciências sobre ética de pesquisa, publicado em 2013 e intitulado "Rigor e Integridade na Condução da Pesquisa Científica: guia de recomendações de práticas responsáveis", onde se pode ler:

Neste Guia, Ciência e Pesquisa são compreendidas de forma ampla. ACiência envolve todo conhecimento sistematizado, obtido por meio de observação, experimentação e raciocínio. Ela busca aumentar a compreensão do mundo natural, físico e social, assim como da mente humana. Nessa dimensão, a Ciência abrange as chamadas Ciências Exatas, Naturais, Sociais e as Humanidades. ${ }^{24}$

Não se trata de dizer então que o conhecimento das Desumanidades se tornou irresponsável (em oposição à responsabilidade pedida no documento), mas de reconhecer que sistematização, observação, experimento, raciocínio (uso racional da mente, portanto) e aumento da compreensão do mundo não parecem fazer parte do ethos atual das Humanidades, que se tornaram Desumanidades exatamente por

\footnotetext{
${ }^{23}$ VATTIMO. O fim da modernidade, p. xix.

${ }^{24}$ ACADEMIA BRASILEIRA DE CIÊNCIAS. Rigor e Integridade na Condução da Pesquisa Cientifica: guia de recomendações de práticas responsáveis, p. 2.
} 
se pautarem, sobretudo, pelo viés desconstrucionista. Portanto, o documento parece desconhecer parte daqueles a quem ele se dirige, o que acarreta enormes mal-entendidos. No interior das faculdades e departamentos de Letras, enfrentamos essa situação, pois uma de nossas duas grandes áreas, a Linguística, se pauta pelos parâmetros apontados; a outra, a Teoria, se pauta pelo oposto. E o diálogo entre elas seria fundamental para o avanço do conhecimento na área, não porque a Teoria deva se mirar nos protocolos da Linguística enquanto ciência, afinal elas são mesmo diferentes em método e objeto, mas apenas porque os universais humanos expressos pela linguagem deveriam ser o horizonte de ambas as disciplinas.

A segunda consequência, e aqui falo especificamente da teoria da literatura, está no fato de que o nosso discurso autorreferente isolou a disciplina de um diálogo além dos muros de nossa aldeia. Falamos apenas para nós mesmos, de especialistas para especialistas. Por isso tomei como epígrafe desta fala o comentário profundo e contundente do crítico literário Tzvetan Todorov:

As análises críticas literárias ou teses escritas sobre a literatura $[\ldots]$ me parecem, hoje em dia, se dirigir quase exclusivamente aos outros especialistas da literatura, enquanto que o romance interessa a todo mundo. E me sinto mais próximo de todo mundo do que dos especialistas em tal ou tal assunto..$^{25}$

Todorov foi um dos maiores praticantes do estruturalismo literário, no interior mesmo da alta cultura francesa dos anos 1960. A certa altura, entretanto, percebeu a falácia do humanismo rebaixado, ou anti-humanismo, e construiu uma visão crítica sobre o assunto, baseado antes de tudo na constatação de que a reflexão e o conhecimento sobre a literatura perdem o sentido se se afastam de seu objeto e de seu leitor. Se nós continuarmos a repetir que o autor morreu, que a literatura morreu e que o homem morreu, pode ser que eles acabem morrendo mesmo, numa espécie de profecia autorrealizável. A meditação do crítico pode servir de guia para todas as outras áreas das ciências humanas e sociais. Que nós possamos aprender com ele os fatos inegáveis de que o valor da literatura permanece, de que o homem permanece como um valor.

${ }^{25}$ TZVETAN Todorov - A literatura em perigo. 
Não se trata aqui de regredir nostalgicamente a uma figura transcendente do homem que se configurasse numa ideia absoluta ou numa ficção política ou religiosa que substituísse o embate com a realidade do mundo. Propor esse retorno seria algo de ingênuo. Mas a literatura - e esse parece ser o fundo do comentário de Todorov - se constitui como um objeto no qual a transcendência se dá no plano mesmo da imanência. A literatura interessa a toda a gente porque ela retira o sujeito de si apenas para fazê-lo voltar a si mesmo em renovado sentido de sua humanidade. A experiência da literatura seria assim uma espécie de transcendência laica, em que o universal não suplanta o particular, o ideal não se opõe ao existencial. Essas figuras gerais apenas fulguram como medida efêmera, mas necessária, do propriamente humano. Nesse sentido é que Todorov, no livro citado, diz que através da leitura de um romance "ascendemos" a uma "compreensão ampliada do mundo humano" ${ }^{26} \mathrm{O}$ verbo "ascender" traz ali a nota transcendente, que no entanto não nega o mundo propriamente humano.

Se a teoria da literatura perde esse valor, perde, como consequência, o contato com o homem comum que busca nas obras que lê algo que dê sentido à sua vida. Seria a literatura apenas então um remédio para a alma? Todorov responde dizendo que não, mas acrescenta: “[...] porém, revelação do mundo, ela pode também, em seu percurso, nos transformar a cada um de nós a partir de dentro". ${ }^{27}$ A teoria da literatura tem muito a ganhar com essa lembrança oportuna.

\section{Referências}

ACADEMIA BRASILEIRA DE CIÊNCIAS. Rigor e Integridade na Condução da Pesquisa Científica: guia de recomendações de práticas responsáveis. Rio de Janeiro: Academia Brasileira de Ciências, 2013. p. 2. BELL, Daniel. The Cultural Contradictions of Capitalism. 2. ed. New York: Basic Books, 1996.

FERRY, Luc; RENAUT, Alain. Pensamento 68: ensaio sobre o antihumanismo contemporâneo. Tradução de Robert Markenson e Nelci do Nascimento Gonçalves. São Paulo: Ensaio, 1988.

${ }^{26}$ TODOROV. A literatura em perigo, p. 81.

${ }^{27}$ TODOROV. A literatura em perigo, p. 76. 
FERRY, Luc. A nova ordem ecológica: a árvore, o animal e o homem. Tradução de Rejane Janowitzer. Rio de Janeiro: Difel, 2009.

FOUCAULT, Michel. As palavras e as coisas. 2. ed. Tradução de Salma Tannus Muchail. São Paulo: Martins Fontes, 1981.

FRIEDRICH, Hugo. Estrutura da lírica moderna. Tradução de Marise M. Curioni. São Paulo: Duas Cidades, 1978.

GELLNER, Ernest. Pós-modernismo, razão e religião. Tradução de Susana Souza e Silva. Lisboa: Instituto Piaget, 1994.

MERQUIOR, J. De Praga a Paris. Tradução de Ana Maria de Castro Gibson. São Paulo: Nova Fronteira, 1991.

NIETZSCHE, Friedrich. Assim falou Zaratustra. Tradução de Paulo César de Souza. São Paulo: Companhia das Letras, 2011.

ORTEGA Y GASSET, José. A desumanização da arte. 5. ed. Tradução e prefácio de Ricardo Araújo. São Paulo: Cortez, 2005.

SCRUTON, Roger. Confessions of a Skeptical Francophile. Disponível em: http://www.roger-scruton.com/articles/1-politics-and-society/83confessions-of-a-sceptical-francophile.html. Acesso em: 11 mar. 2019.

SCRUTON, Roger. Gentle Regrets. New York: Continuum, 2006.

SCRUTON, Roger. Modern Philosophy: an introduction and survey. 2 ed. NYC: Penguin, 1995. Cap. 1: The Nature of Philosophy, p. 1-15; Cap. 30: The Devil, p. 458-480.

TALLIS, Raymond. In Defense of Realism. 2. ed. Lincoln; London: University of Nebraska Press, 1998.

TODOROV, Tzvetan. A literatura em perigo. Tradução de Caio Meira. São Paulo: DIFEL, 2009.

TZVETAN TODOROV - A literatura em perigo. [S.l.: s.n.], 2013. 1 vídeo (1:47 min). Publicado pelo canal Fronteiras do Pensamento. Disponível em: http://www.youtube.com/watch?v=abOhgt_e3-Y. Acesso em: 27 mar. 2014.

VATTIMO, Gianni. O fim da modernidade. São Paulo: Martins Fontes, 1996. VOEGELIN, Eric. Hitler e os alemães. Tradução de Elpídio Mário Dantas Fonseca. São Paulo: É Realizações, 2008.

Recebido em: 28 de janeiro de 2019. Aprovado em: 8 de julho de 2019. 